\title{
Adolf Januszkiewicz jako pośrednik oraz spoiwo lączące kulturę kazachską i europejską
}

$\mathrm{K}$ azachowie ze szczególną życzliwością traktują zagranicznych intelektualistów, którzy poznawszy unikatowość kazachskiej kultury i historii, swoją twórczością wznosili most pomiędzy daleką stepową krainą a Europą. Wśród pierwszych, którzy tego dokonali, byli wielcy synowie polskiego narodu: G. Zieliński, B. Zaleski, A. Januszkiewicz i S. Gross. Zostawili oni potomnym niestarzejące się dziedzictwo literackie o bycie i tradycjach mieszkańców stepu. Szczególnie ciekawe i bogate jest dziedzictwo takich działaczy, jak A. Januszkiewicz i G. Zieliński, w związku $\mathrm{z}$ zawarciem w ich pracach wielu istotnych informacji na temat codziennego i duchowego życia Kazachów. Stanowią one ciekawe źródło informacji nawet w dzisiejszych czasach.

Bohater artykułu już jako dziecko potrafił myśleć przyszłościowo, analizował bieżące wydarzenia, dorastał w atmosferze wielkiego zamiłowania do swobody propagowanej przez Kościuszkę, który był jego dalekim kuzynem. Januszkiewicz z lat dzieciństwa próbował naśladować bohatera walki o niepodległość narodu polskiego.

Po ukończeniu z wyróżnieniem gimnazjum w Winnicy, rozpoczął studia polonistyczne na Uniwersytecie w Wilnie. W tym okresie młody patriota nawiązuje kontakt z Towarzystwem Filomatów, wśród założycieli którego był również Adam Mickiewicz. Znany jest fakt, że wielu liderów ruchów demokratycznych był związanych z tą organizacja, m.in. dekabryści rosyjscy (Yanushkvich, 1978, s. 542).

Po ukończeniu studiów i powrocie do rodzinnych stron, Januszkiewicz utrzymuje ciagły kontakt z filomatami. W tym czasie zdobywa uznanie jako utalentowany literat. W 1821 r. na łamach „Dziennika Wileńskiego” ujrzał światło dzienne jego pierwszy utwór - poemat sentymentalny Meliton $i$ Ewelina. Januszkiewicz należał do grona miłośników twórczości A. Mickiewicza, będąc jednym z największych badaczy i popularyzatorów jego poezji na Podolu. 
W 1826 r. pracuje w Wydziale Sądu Cywilnego w Kamieńcu Podolskim. Z powodu pogarszającego się stanu zdrowia rezygnuje z tej pracy i wyjeżdża na leczenie do Niemiec, Włoch i Francji. W 1829 r. Januszkiewicz spotkał się w Rzymie z przebywającymi tam Mickiewiczem i Odyńcem (polskim poetą również należącym do grona filomatów).

Po powrocie we wrześniu 1830 r. do ojczyzny, A. Januszkiewicz bierze udział w powstaniu listopadowym. Podczas jednego z wystąpień zbrojnych zostaje ranny i dostaje się do niewoli. 4 kwietnia 1832 r. rosyjski sąd skazuje go na karę śmierci, która następnie zostaje zamieniona na karę zesłania na Syberię. Jednocześnie pozbawiono go tytułu szlacheckiego i skonfiskowano majątek.

Od tej pory, a mianowicie od 1833 r., w życiu Januszkiewicza rozpoczyna się zupełnie nowy etap, ściśle związany z ziemią kazachską.

Początkowo Januszkiewicz odbywał karę w Tobolu; później, w 1835 r. zostaje przeniesiony do Esyla. Przywiózł on ze sobą niedużą bibliotekę domowa, a w niej periodyki tamtych lat. Ta biblioteka stała się dla innych zesłanych ucieczką od rzeczywistości i prawdziwym skarbem, który zastępował im cały świat.

Przebywając w Esylu, Januszkiewicz spotkał A. Odojewskiego i G. Zielińskiego, który pod jego wpływem napisze później swój znany poemat romantyczny Kirgiz. W utworze opisuje tradycje i codzienny byt Kazachów (w Imperium Rosyjskim nazywano ich Kirgizami). Znaczenie utworu G. Zielińskiego jest nieocenione, pozwolił on Europejczykom zobaczyć świat Kazachów oczami pełnymi ciekawości i zachwytu nad wiekowymi tradycjami koczowniczego ludu (Zieliński, 1974, s. 596-597).

W 1841 r. Januszkiewicza przeniesiono do Omska, gdzie pełni on obowiązki pracownika kancelarii sądu okręgowego. Później trafia do Straży Granicznej Obwodu Sybirskich Kirgizów. Począwszy od 1845 r. odbywał podróże do Średniego i Starszego Żuzów (ponadplemienna grupa polityczno-ustrojowa u Kazachów), które znajdowały się pod zarządem Pogranicznego Naczelnika generała Wiszniewskiego. Mając codzienny kontakt z Kazachami, Januszkiewicz opanował ich język. Wszystko, co zobaczył w bezkresnych stepach i doświadczył wśród Kazachów, opisał w swoim dzienniku.

Dzienniki i listy Januszkiewicza stały się dla kazachskich badaczy i historyków źródłem bezcennych informacji.

W 1853 r. Januszkiewicz został przeniesiony do Niżnego Tagiłu Permskiej Guberni, gdzie został kierownikiem pierwszej w tym mieście biblio- 
teki, która swego czasu była otwarta przez rosyjskiego poetę i właściciela kopalni uralskich, hrabiego A. Demidowa.

Prześladowany przez władze caratu, Januszkiewicz, jak gdyby prowadzony przez Stwórcę, trafił do kraju Kazachów, by pozostawić potomnym cenne informacje z tego okresu. W 1856 r. Januszkiewicz zostaje ułaskawiony i powraca do ojczystego kraju. Rok później niestety umiera. W jego Dziennikach i listach widać, jak bardzo bliskie jego sercu są stepy kazachskie i zamieszkujący je lud. On nie tylko opisuje, co zobaczył i usłyszał, ocenia każde wydarzenie, dzieli się swoimi przemyśleniami, wyciaga wnioski.

Obecnie w Kazachstanie na wielu płaszczyznach jest poruszany temat zagrożenia języka kazachskiego. Omawiamy je i staramy się rozwiązać, a Januszkiewicz pisze o języku kazachskim w taki sposób, że wywołuje w nas uczucie wstydu. W jednym z jego listów adresowanym 17 maja 1848 r. do mieszkającego w Polsce brata, Januszkiewicz opisując miasto Semej (Semipalatińsk), w którym się zatrzymał, podróżując po kazachskich stepach, pisze: „W Semipalatińsku zbudowanym na miejscu zniszczonych dżungarskich osad, populacja wynosi ok. 7000 mieszkańców, większość stanowią Tatarzy, taszkentczycy, bucharczycy. W mieście zatem jest sześć czy siedem meczetów i jedna cerkiew. Wszędzie używa się języka kazachskiego. Nawet połowa nadzwyczaj kulturalnej i inteligentnej w tych stronach ludności rosyjskiej biegle posługuje się tym językiem, podobnie do naszych miłych pań mówiących po francusku" (Januszkiewicz, 1979, s. 23). Jest to dowód na to, że status języka kazachskiego był niebywale wysoki i utrzymywał się na tym poziomie aż do nadejścia totalitarnej władzy radzieckiej.

W innym swoim liście, wysłanym 22 maja również do swojego młodszego brata Januariusza, podróżnik pisze o tym, jak kazachskie rodziny cenią czystość i swoją rodzimą kulturę. Wędrowcy często zatrzymywali się na kolację u gospodarzy, co opisał bratu w liście: „Dobrze znający lokalne tradycje i obyczaje Wiktor zwrócił mi w dość dobitny sposób uwagę, że nie przestrzegam ogólnie przejętych tutaj zasad. Okazało się, że przeszkodziłem Wiktorowi, który był w trakcie mycia rąk, podstawiając również własne pod cieknącą wodę. A tego nie wolno było robić. Każdy z nas powinien umyć się osobno, przy czym nie wolno stać, a trzeba kucnąć. Nie wiedziałem, że tak powinno się robić. I jeszcze jeden rażący błąd wprawił mnie w zakłopotanie: będąc głodny, wyciągnąłem wielki kawał mięsa i zacząłem go gryźć. Okazało się, że mięso wcześniej powinno być pokrojone na drobne kawałki. Niezbędny do tego nóż wisi przypięty do pasa każdego stepowca" (Januszkiewicz, 1979, s. 30). 
Jak można zauważyć na podstawie przytoczonego fragmentu listu Januszkiewicza, w dawnych czasach Kazachowie przywiązywali wielką wagę do tradycji i swoistej dla ich środowiska czystości.

Wiele mówi się na temat negatywnego wpływu alkoholu i tytoniu, jednak warto zwrócić uwagę na to, jaki był stosunek Kazachów do używek w XIX wieku:

„Po kolacji, kiedy zapaliliśmy, zdziwiony młody Kazach zapytał Wiktora:

- Co robicie? Palicie coś?

- Palimy cygara.

- A co to jest?

- To zwinięte liście tytoniu.

- A ile to kosztuje?

- Pięć kopiejek.

- A ile cygar palisz codziennie?

- Zwykle około piętnastu.

- Moje biedactwo, jesteś w dodatku głupi! Byłoby lepiej, gdybyś zbierał te monety do kieszeni.

Nie mogliśmy zaprzeczyć, słysząc tę gorzką prawdę" (Januszkiewicz, 1979, s. 31).

Na podstawie tego dialogu możemy wnioskować, jak czysta pierwotnie była natura Kazachów tamtych czasów. Z drugiej zaś strony jest w tym również coś, co moglibyśmy dzisiaj określić jako psychologia komercyjna czy rynkowa.

Objeżdżając letnie pastwiska, Januszkiewicz poznał osobliwości kultury Kazachów, niejednokrotnie zanurzając się w ich samobytny i oryginalny świat wewnętrzny. Pisze o istniejącym u Kazachów przykazaniu, które mówi: „troskliwy stosunek do ziemi, na której mieszkają, stanowi podstawowy obowiązek człowieka", o czym autor listów niejednokrotnie się przekonał.

Wielu współczesnych badaczy podziwia przezorność podróżnika z Polski. Jako dowód na to może posłużyć następujący fakt. W swoim liście, wysłanym 31 maja z Ajagoza, A. Januszkiewicz pisze: „Odnowiony Ajagoz rośnie niczym kwitnący purpurowy kwiat. Oprócz państwowych budynków przeznaczonych na garnizony wojskowe i administrację, w miejscowości jest kilka budowli drewnianych. W przyszłości Ajagoz może zostać jednym ze znaczących miast. Tylko tutaj można obserwować tendencje podobne do tych, które występują w Stanach Zjednoczonych. Europie z liczebną populacją zjawisko to nie jest znane - niczym spod zie- 
mi wyrastają jak grzyby nowe miejscowości. Na przykład Akmoła jest przyszła stolica catej stepowej krainy. Aktau, Atbasar, Kokpekty, Kusmuryn - wszystkie te miejscowości powstały i rosły na moich oczach" (Januszkiewicz, 1979, s. 57). Nie można nie wspomnieć, że Januszkiewicz zasiadał na najlepszym wierzchowcu stepowej krainy. Już w XIX wieku potrafił przewidzieć, że Akmoła (dziś nazywa się Astana) będzie w przyszłości stolicą niepodległego Kazachstanu.

W kazachskim społeczeństwie imię Abaja Kunanbajewa zajmuje szczególne miejsce. Jest on największym klasykiem kazachskiej literatury. Zaskakujący jest fakt, że Januszkiewicz po raz kolejny potrafił zajrzeć w przyszłość. W swoim dzienniku pisze on, że spotkał się z głową tobyktyńskiego rodu Kunanbajem Uskienbajewem, ojcem Abaja. Januszkiewicz podkreśla, że był to nietuzinkowy, mądry człowiek (Januszkiewicz, 1979, s. 173, 178).

Wzniesiony dzięki Januszkiewiczowi most pomiędzy polskim a kazachskim narodami ciągle się umacnia i rośnie. Na początku XX wieku młodzi Kazachowie kształcili się na uniwersytetach w Polsce. Z reguły byli oni studentami prawa Uniwersytetu Warszawskiego, a także Instytutu Weterynaryjnego. Wśród studentów, którzy w 1914 r. pomyślnie ukończyli studia i powrócili do swojego kraju byli m.in.: K. Boranbajew (Ałmaty), A. Kuszikow i A. Szałymbiekow (Semej), Ż. Sołtanajew (Siedmiorzecze), A. Tungaszin (Turgaj), Ualijew.

Po odzyskaniu przez Kazachstan niepodległości tradycja ta rozwija się na szerszą skalę. Obecnie na wielu polskich uczelniach studiuje bądź odbywa staże setki studentów z Kazachstanu.

W Kazachstanie natomiast również dzisiaj znajduje się dość liczna Polonia, głównie w obwodach Akmolińskim, Karagandyjskim, Pawłodarskim i Kostanajskim, a najwięcej w obwodzie Północno-Kazachstańskim. W kraju funkcjonuje Związek Polaków Kazachstanu (ZPK), będący częścią Zgromadzenia Narodu Kazachstanu. Polacy w Kazachstanie dążą do odrodzenia polskich tradycji, pamięci historycznej, umocnienia relacji z Polską, a także intensyfikacji nauki języka polskiego. Polacy żywią do Kazachów uczucie wdzięczności, doceniają przyjaźń z innymi narodami, zamieszkującymi Kazachstan.

ZPK powstał w 1989 roku w Kokszetau z inicjatywy Anatola Diacińskiego. Kolejne stowarzyszenia powstały w Karagandzie, Ałmaty i innych miastach. Zostały zarejestrowane w 1992 r., a następnie zjednoczyły się w ZPK. W poszczególnych obwodach działa 13 oddziałów tego związku. 
Po odzyskaniu niepodległości Kazachstanu pojawił się nowy impuls w rozwoju kazachstańskiej Polonii. Każdego roku prawie 100 osób mających pochodzenie polskie podejmuje naukę na uniwersytetach w Polsce. Razem z nimi studiują Kazachowie, Rosjanie, Koreańczycy, Ukraińcy i inni obcokrajowcy. Dodać należy, że wiodące uniwersytety kraju, a mianowicie Uniwersytet w Kokszetau i Narodowy Uniwersytet Pedagogiczny im. Abaja w Ałmaty kształcą młodzież na kierunku „Język polski i literatura".

W 2011 roku w murach Uniwersytetu w Karagandzie w 75. rocznicę stalinowskiej deportacji Polaków z Ukrainy do Kazachstanu odbyła się międzynarodowa teoretyczno-praktyczna konferencja. Wielu Polaków przyjechało wtedy do Karagandy. Na konferencji dzielono się wspomnieniami z okresu terroru, analizowano przeszłość, teraźniejszość i przyszłość, by podobne wydarzenie już nigdy nie miało miejsca.

Karagandyjskie stowarzyszenie „Polonia” zdobyło duże doświadczenie w trakcie kulturowej i edukacyjnej pracy wśród Polaków. W. Chmielowski, przewodniczący stowarzyszenia „Polonia” mówi, że stosunki z Polską ciagle się umacniają. Zgodnie z założeniami „Wspólnota Polska” pomaga dzieciom utalentowanym, przejawiającym szczególne zdolności do nauki języka polskiego. Około 20-25 dzieci co roku odwiedza Polskę w celu zdobycia wiedzy z zakresu historii, języka i kultury.

W konferencji w Karagandzie wzięli udział przedstawiciele Kazachstanu, Polski i Rosji. Polska diaspora w Kazachstanie była reprezentowana przez delegatów między innymi z obwodów Pawłodarskiego, Kostanajskiego i Północno-Kazachstańskiego. W trakcie konferencji odbyła się wystawa „Polacy w Kazachstanie” oraz projekcja filmu o deportacji Polaków.

Wszystkie te przedstawione wyżej wydarzenia są tematycznie powiązane z niniejszym artykułem. Duchowe dziedzictwo wybitnego Polaka A. Januszkiewicza stanowi bezcenny wkład w rozwój tradycyjnych duchowych stosunków pomiędzy narodami. W ostatnim czasie często miały miejsce konferencje, które poruszały polską problematykę, w tym tradycje kulturowe w oparciu o bogate dziedzictwo literackie, twórczość wielkich Polaków, wśród których jest podróżnik i odkrywca Adolf Januszkiewicz.

Stosunki kazachsko-polskie ulegają regularnym umocnieniom. Kazachowie są wdzięczni Januszkiewiczowi za jego działalność humanistyczną w ich ojczyźnie. Jego książki ukazują się w znacznych nakładach i cieszą się zainteresowaniem wśród czytelników. Stwierdzenie z początku 
artykułu, dotyczące wzniesienia złotego mostu pomiędzy oboma narodami nie jest zatem nadużyciem.

\section{Bibliografia}

Januszkiewicz A. (1979), Dzienniki i listy (w języku kazachskim), Ałmaty.

Yanushkvich A. (1978), Qazaq Sovet Entiklopediasy, t. XII.

Zieliński G. (1974), Qazaq Sovet Entiklopediasy, t. IV.

\section{Summary}

\section{Adolf Januszkiewicz as an intermediary and link between Kazakh and European culture}

The paper is devoted to the role played by Adolf Januszkiewicz, a poet and insurgent in the November uprising, in Polish-Kazakh relations. A graduate of Vilnius University, Januszkiewicz was among eminent Polish activists sent by the Tsar into exile in Siberia and Kazakhstan. Over twenty years spent in close contact with the inhabitants of the Great Steppe shaped Januszkiewicz's peculiar attitude to the Kazakh nation. His journals and letters have been translated into several European languages. They still remain an interesting source of knowledge about the culture and customs of Kazakhs then. They are highly appreciated in Kazakhstan as an example of the thorough approach taken by an educated representative of a progressive European culture towards the life of a nomadic people. The positive image of Poles generated by the $19^{\text {th }}$ century exiles has laid the foundations for the friendly attitude the Kazakh have had towards successive groups of Poles who found themselves in their country. At present, the sizeable Polish minority is well integrated with Kazakh society. The legacy of such activists as Adolf Januszkiewicz provides excellent foundations for the advancement of Polish-Kazakh relations. 